\title{
Abdominal ultrasound augments the medical students' ability to identify free intraabdominal fluid
}

\author{
Gabriela Cumani Toledo ${ }^{1 * ~(1)}$, Alyne Schreider ${ }^{1}$ (D), Gustavo Bittencourt Camilo ${ }^{1}$ (1), \\ Fernando Antonio Basile Colugnati ${ }^{1}\left[\mathbb{D}\right.$, Natalia Maria da Silva Fernandes ${ }^{1}(\mathbb{D}$, \\ Marcus Gomes Bastos $1,2,3$
}

\section{SUMMARY}

OBJECTIVE: Free intra-abdominal fluid describes an accumulation of free fluid in the peritoneal cavity. It has different etiologies, but it frequently constitutes a meaningful clinical sign. In this study, the authors interrogate whether abdominal ultrasound augments the medical students' ability to identify free intra-abdominal fluid.

METHODS: Thirty-one medical students without any previous formal ultrasound training were subjected to cognitive assessment before and after four and a half-hour of theoretical lecture and hands-on course about the diagnosis of free intra-abdominal fluid by physical examination and abdominal ultrasound. The hands-on sessions were done in healthy volunteers with a simulated peritoneal catheter and in patients treated with peritoneal dialysis with different amounts of dialysate in their cavity.

RESULTS: The cognitive assessment before and after the course increased from $6.7 \pm 2.3$ to $11.6 \pm 1.1$ points $(p<0.0001)$. The sensitivity, specificity, and accuracy in the diagnosis of free intra-abdominal fluid were higher when students used abdominal ultrasound. The students agree with the inclusion of abdominal ultrasound in the diagnose of free intra-abdominal fluid in the undergraduate curriculum.

CONCLUSIONS: This study demonstrates that incorporating abdominal ultrasound is feasible and improves medical students' short-time competency in performing and interpreting the findings diagnostic of free intra-abdominal fluid.

KEYWORDS: Education, medical. Students, medical. Molecular Docking Simulation. Ultrasonography. Focused assessment with sonography for trauma.

\section{INTRODUCTION}

Thoracoabdominal trauma is the leading cause of death among young individuals ${ }^{1}$. The majority of traumatic injuries are blunt, followed by intra-peritoneal bleeds ${ }^{2}$, and responsible for deaths secondary to hypovolemic shock ${ }^{3}$. Therefore, the quick diagnosis of free intra-abdominal fluid (FIAF) following thoracoabdominal trauma is paramount. Ideally, an ideal FIAF assessment should be rapid, accurate, and non-invasive ${ }^{3}$.

Point-of-care ultrasonography (POCUS) is a safe and rapidly evolving diagnostic modality that has significantly impacted patients' evaluation and treatment in various conditions $s^{4,5}$. It has various advantages, including its bedside assessment, ease of

\footnotetext{
Universidade Federal de Juiz de Fora, Faculdade de Ciências Médicas e da Saúde de Juiz de Fora, Programa de Pós-graduação em Saúde - Juiz de Fora (MG), Brasil.

${ }^{2}$ Centro Universitário Governador Ozanam Coelho, Faculdade de Medicina - Ubá (MG), Brasil.

${ }^{3}$ Fundação Instituto Mineiro de Estudos e Pesquisas em Nefrologia - Juiz de Fora (MG), Brasil.

${ }^{*}$ Corresponding author: gabrielacumani9@gmail.com

Conflicts of interest: the authors declare there are no conflicts of interest. Funding: none.

Received on July 05, 2020. Accepted on August 08, 2020.
} 
use, non-invasiveness, no use of radiation or contrast agents, and is inexpensive $e^{4,6}$.

Since the middle of the last decade, many medical schools in North America have been implementing POCUS in their undergraduate curricula to improve physical examination (PE) teaching ${ }^{7-11}$. Interestingly, FIAF was listed as one of the ninety core clinical milestones that all graduating medical students should obtain before graduation ${ }^{12}$.

POCUS in the identification of FIAF is well-described among physicians, but so far, it is still little taught to medical students ${ }^{6,13,14}$. We hypothesized that short-term abdominal ultrasound (AUS) training would improve students' skills to identify FIAF. The objective of this study was to determine whether AUS augments medical students' ability to identify FIAF.

\section{METHODS}

Patients who expressed willingness to participate in the study were recruited and treated with automated peritoneal dialysis (APD) in the dialysis unit of the University Hospital of Universidade Federal de Juiz de Fora. Two APD male patients had been on treatment for less than 12 months, and one female patient had been under treatment for 20 years. Two healthy volunteers were included to demonstrate the normal ultrasonography anatomy of the abdomen and pelvic cavity. The exclusion criteria were: 1. Patients suspected with peritonitis; 2. Patients who were unable to assume the supine position.

Medical students of the $5^{\text {th }}$ period of the medical course from the School of Medicine of Universidade Federal de Juiz de Fora and Faculty of Medical and Health Sciences of Juiz de Fora (SUPREMA), who had already attended the disciplines of anatomy and semiology and without prior hands-on experience with ultrasound were invited in their classrooms to participate. They were clarified about the study, and consent was implied if the participants, students, and volunteers, showed up on the day of the course and signed the written informed consent. The Ethics Committee approved the study (CAAE No. 91487618.3.0000.5147).

\section{Study Protocol}

A questionnaire with 15 multiple-choice questions, each one with four options, was applied on day one. The test aimed to evaluate previous knowledge regarding the physical principles of ultrasound, ultrasound artifacts, types of transducers, image generation, and interpretation in the normal abdomen, presence of FIAF, and PE findings in healthy condition and ascites. Then, a four and a half hour course, including didactic lecture (one hour) and practical demonstration (three and a half hours), was held. The hands-on session was done on one health volunteer and an APD patient with two liters of peritoneal solution.
Traditional bedside physical signs were reviewed. In the AUS training, the convex probe connected to an ultrasound equipment (Terason uSmart 3200T system, Burlington, MA) was used, initially with the probe placed in the right upper quadrant (RUQ) at the mid-axillary line using the coronal plane. The students were taught to identify the diaphragm, liver tip, hepatorenal interface, and the presence of FIAF, which appears as an anechoic stripe. In the left upper quadrant (LUQ), the students were trained to place the probe at the posterior-axillary line using coronal plane to identify the spleen, the diaphragm, and the left kidney. FIAF was captured beneath the diaphragm, spleen tip, splenorenal recess, and the inferior left kidney. Finally, in the pelvic cavity (PC), the medical students were trained to identify free fluid posterior/inferior or lateral to the bladder using sagittal and transverse planes. Two instructors (GC and MGB) supervised students individually (Figure 1).

Day one:

31 undergraduate medical students (5th period)

$\downarrow$

Cognitive assessment (15 multiple choice questions) on ultrasound physics, image adjustment, transducers, PE, and AUS in the diagnosis of IAFF

Four and a half-hour course on diagnosis of IAFF: 1 hour of didactic lecture +3.5 hour of hands-on session on PE (flank dullness, shifting dullness on percussion and fluid thrill or wave) and AUS (RUQ, LUQ, and pelvic cavity) in healthy models and APD patients

\section{Day two:}

Practical assessment on IAFF (PE and AUS): Three APD patients, one with drained cavity, one with $1 \mathrm{~L}$ and, one with $2 \mathrm{~L}$ of dialysis solutions, and two healthy individuals with a simulation of dialysis catheter implanted in their abdomen

Cognitive assessment (15 multiple choice questions) on ultrasound physics, image adjustments, transducers, $\mathrm{PE}$, and abdominal US in the diagnosis of IAFF

Anonymous questionnaire about student learning experience

PE: physical examination; AUS: abdominal ultrasound; IAFF: intraabdominal free fluid; RUQ: right upper quadrant; LUQ: left upper quadrant; APD: automated peritoneal dialysis; US: ultrasound.

Figure 1. Work-flow chart 
On day two, students were subjected to practical assessment of FIAF in two healthy volunteers with peritoneal catheter simulating insertion in the abdominal cavity, and in three APD patients, one with drained abdominal cavity, another with one liter of peritoneal solution, and a third patient with two liters of dialysate. Initially, one student at a time was instructed to use PE to answer yes or no to the question: "Is there FIAF"? After that, the same question was repeated with the student using AUS. Two researchers documented the students' responses. After the practical assessment, a second questionnaire with 15 multiple-choice questions, each with four options, and covering the same topics as those of the pre-course was applied. Finally, using a five-point Likert scale, the students completed an anonymous questionnaire about their learning experience with the course.

\section{Statistics}

A descriptive analysis was performed using means and percentages according to the characteristic of the variable. The cognitive assessment was compared before and after the course, using the Student's $t$-test for paired samples. FIAF by AUS was considered present if identified in one or more abdominal windows (RUQ and/or LUQ and/or pelvic cavity). Kappa statistics were used to assess the concordance between PE and AUS performed by the students. Additionally, compared to the radiologist's assessment, the sensibility and specificity of the PE and AUS were assessed using classic diagnostic test properties concepts. A 95\% confidence interval was considered, using the software SPSS 17.0, Chicago, Illinois.

\section{RESULTS}

The study included 31 medical students (mean age 21.54 1.38 years; females $64.5 \%$ ) and five human models. Cognitive assessment scores improved from before the course $(6.7 \pm 2.3)$ to after its completion $(11.6 \pm 1.1) \mathrm{p}<0.0001$.

In total, 372 abdomens were examined, 52 in healthy volunteers with a simulated peritoneal catheter, and 320 in APD patients. The abdominal cavity was examined with the PE 93 times and with the AUS 279 times. The study showed the diagnosis of FIAF by medical students using PE and AUS distributed in the absence (simulated peritoneal catheter) and presence (including drained abdominal cavity, abdomen with one litter, and two litter of dialysate) of FIAF. The agreement ( $k$-value) between students was 0.88 for PE and 0.95 for AUS.

Compared to PE, AUS increased sensitivity (66.25 to $90.0 \%)$, specificity (7.69 to $82.05 \%$ ), and accuracy (58.06 to $88.88 \%$ ) for the diagnosis of FIAF.
Figure 2 shows students' anonymous responses about their opinion regarding the course. In general, the students approved the course.

\section{DISCUSSION}

Almost 15 years after the inclusion of ultrasound teaching to undergraduate students in North America, the vast majority of medical schools in Brasil has not yet integrated ultrasound in undergraduate medical education. Our study shows that students' ability to identify FIAF is much higher using AUS compared to PE of the abdomen.

Previous studies have shown that residents and faculty in radiology and emergency medicine can accurately diagnose FIAF using ultrasound ${ }^{7,15-19}$. Although FIAF assessment has been included as part of the final Core Medical Student Clinical Ultrasound Milestones that all graduating medical students should obtain before graduation, this training is not yet definitively proven feasible among undergraduate medical students ${ }^{12}$. Measurable benefits of teaching ultrasound at the undergraduate level include comparing cognitive improvement between pre- and post-training and psychomotor skill enhancement ${ }^{16,20}$. Our study suggests that a short training significantly improved the students' scores of the cognitive assessment, a success rate similarly described in other studies ${ }^{21,22}$.

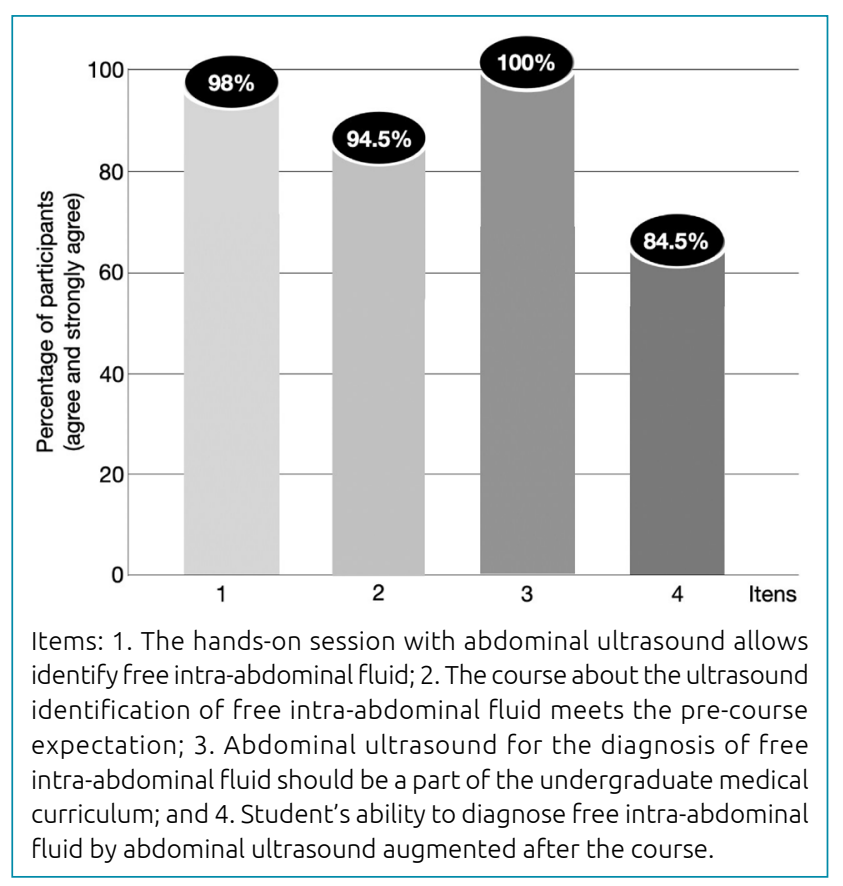

Figure 2. Anonymous questionnaire about student's experience with the course 
AUS in the diagnosis of FIAF requires visual and psychomotor coordination. It is a skill that can be learned in a modest amount of ultrasound training. To train and assess the medical students' ability to identify FIAF correctly, we took advantage of a kind of treatment patients with end-stage renal failure are subjected to, the APD. As none of the three APD patients presented an empty abdominal cavity, a finding that the students were unaware of, two healthy volunteers with the simulated peritoneal catheter were included, thus, guaranteeing the absence of FIAF. As it was observed, our students' ability to exclude or confirm FIAF with AUS was superior compared to PE in sensitivity (66.25 to $90.0 \%$ ), specificity ( 7.69 to $82.05 \%$ ), and accuracy (58.06 to $88.88 \%$ ). A comparison of these results with others is difficult since similar studies are scarce. One study noted that first-year medical students randomized to assess ascites with PE and AUS having a radiologist as a reference showed sensitivity, specificity, and accuracy similar to ours, but differed in the fact that there was no statistical difference between the groups ${ }^{23}$.

In the APD patients, identification of FIAF by our students was more frequently diagnosed in Morrison's pouch (97.5\%) when compared to the LUQ $(93.7 \%)$ and pelvic cavity $(78.75 \%)$. In supine patients, free fluid first collects in the most dependent portion of the abdominal cavity, the RUQ ${ }^{22}$. However, FIAF was mistakenly diagnosed in the RUQ (46\%) in the two healthy volunteers with no free fluid in their abdominal cavities. One possible explanation for this percentage of incorrect diagnosis is that one volunteer had been fasting for almost 12 hours before the exam and presented a full gall bladder, which led students to have it mistaken by FIAF.

A common argument against implementing POCUS training at medical schools is the perceived significant time requirements for teaching $\mathrm{it}^{24}$. However, as previously shown in other publications, our study shows that ultrasound training consumes little time to be effectively taught ${ }^{21,22}$. Medical students able to perform POCUS efficiently at the end of their course have a higher chance of practicing and implementing it in the residency and later in their practice ${ }^{24,25}$.

Some limitations are recognized in our study. First, the number of students included was small. Second, only shortterm knowledge was assessed. Last, even though the volunteers used had free fluid in their cavity to simulate distinct conditions of FIAF, the study condition was quite favorable, different from the stressful clinical environment of the abdominal trauma, which can negatively affect the students' performance.

\section{CONCLUSION}

Results suggest that medical students' short-term training with AUS is an available, fast, and reliable test of high sensitivity, specificity, and accuracy in identifying FIAF. AUS is a diagnostic tool, and students enjoyed its learning and, therefore, should be an indispensable part of the undergraduate medical curriculum.

\section{AUTHORS" CONTRIBUTION}

GCT: Conceptualization, Methodology, Writing - Original Draft, Writing - Review \& Editing. GBC: Conceptualization, Methodology, Writing - Original Draft, Writing - Review \& Editing. MGB: Conceptualization, Methodology, Writing Original Draft, Writing - Review \& Editing. FABC: Data Curation, Methodology, Writing - Original Draft, Writing - Review \& Editing. NMSF: Data Curation, Methodology, Writing - Original Draft, Writing - Review \& Editing. AS: Data Curation, Methodology, Writing - Original Draft, Writing - Review \& Editing.

\section{REFERENCES}

1. Teixeira PG, Inaba K, Hadjizacharia P, Brown C, Salim A, Rhee $P$, et al. Preventable or potentially preventable mortality at a mature trauma center. J Trauma. 2007;63(6):1338-46. https:// doi.org/10.1097/TA.0b013e31815078ae

2. Melniker LA, Leibner E, McKenney MG, Lopez P, Briggs WM, Mancuso CA. Randomized controlled clinical trial of pointof-care, limited ultrasonography for trauma in the emergency department: the first sonography outcomes assessment program trial. Ann Emerg Med. 2006;48(3):227-35. https:// doi.org/10.1016/j.annemergmed.2006.01.008

3. Pearl WS, Todd KH. Ultrasonography for the initial evaluation of blunt abdominal trauma: a review of prospective trials. Ann Emerg Med. 1996;27(3):353-61. https://doi.org/10.1016/ s0196-0644(96)70273-1
4. Moore $\mathrm{CL}$, Copel JA. Point-of-care ultrasonography. $\mathrm{N}$ Engl J Med. 2011;364(8):749-57. https://doi.org/10.1056/ NEJMra0909487

5. Cormack CJ, Coombs PR, Guskich KE, Blecher GE, Goldie N, Ptasznik R. Collaborative model for training and credentialing point-of-care ultrasound: 6-year experience and quality outcomes. J Med Imaging Radiat Oncol. 2018;62(3):330-6. https://doi.org/10.1111/1754-9485.12697

6. Scalea TM, Rodriguez A, Chiu WC, Brenneman FD, Fallon WF Jr, Kato K, et al. Focused Assessment with Sonography for Trauma (FAST): results from an international consensus conference. J Trauma. 1999;46(3):466-72. https://doi.org/10.1097/00005373199903000-00022 
7. Hoppmann R, Cook T, Hunt P, Fowler S, Paulman L, Wells J, et al. Ultrasound in medical education: a vertical curriculum at the University of South Carolina School of Medicine. J S C Med Assoc. 2006;102(10):330-4. PMID: 17703842

8. Rao S, van Holsbeeck L, Musial JL, Parker A, Bouffard JA, Bridge $P$, et al. A pilot study of comprehensive ultrasound education at the Wayne State University School of Medicine: a pioneer year review. J Ultrasound Med. 2008;27(5):745-9. https://doi.org/10.7863/jum.2008.27.5.745

9. Bahner DP, Adkins EJ, Hughes D, Barrie M, Boulger CT, Royall NA. Integrated medical school ultrasound: development of an ultrasound vertical curriculum. Crit Ultrasound J. 2013;5(1):6. https://doi.org/10.1186/2036-7902-5-6

10. Fox JC, Chiem AT, Rooney KP, Maldonaldo G. Web-based lectures, peer instruction and ultrasound-integrated medical education. Med Educ. 2012;46(11):1109-10. https://doi. org/10.1111/medu.12039

11. Steinmetz P, Dobrescu O, Oleskevich S, Lewis J. Bedside ultrasound education in Canadian medical schools: a national survey. Can Med Educ J. 2016;7(1):e78-86. PMID: 27103956

12. Dinh VA, Lakoff D, Hess J, Bahner DP, Hoppmann R, Blaivas M, et al. Medical Student Core Clinical Ultrasound Milestones: a consensus among directors in the United States. J Ultrasound Med. 2016;35(2):421-34. https://doi.org/10.7863/ ultra.15.07080

13. Rozycki GS, Ochsner MG, Schmidt JA, Frankel HL, Davis TP, Wang $D$, et al. A prospective study of surgeon-performed ultrasound as the primary adjuvant modality for injured patient assessment. J Trauma. 1995;39(3):492-8. https://doi. org/10.1097/00005373-199509000-00016

14. Rozycki GS, Ochsner MG, Jaffin JH, Champion HR. Prospective evaluation of surgeons' use of ultrasound in the evaluation of trauma patients. J Trauma. 1993;34(4):516-26. https://doi. org/10.1097/00005373-199304000-00008

15. Abu-Zidan FM, Zayat I, Sheikh M, Mousa I, Behbehani A. Role of ultrasonography in blunt abdominal trauma: a prospective study. Eur J Surg. 1996;162(5):361-5. PMID: 8781916

16. Shackford SR, Rogers FB, Osler TM, Trabulsy ME, Clauss DW, Vane DW. Focused abdominal sonogram for trauma: the learning curve of nonradiologist clinicians in detecting hemoperitoneum. J Trauma. 1999;46(4):553-62. https://doi. org/10.1097/00005373-199904000-00003

17. Radwan MM, Abu-Zidan FM. Focussed Assessment Sonograph Trauma (FAST) and CT scan in blunt abdominal trauma: surgeon's perspective. Afr Health Sci. 2006;6(3):187-90. https://doi.org/10.5555/afhs.2006.6.3.187

18. Kim DY, Yelle JD, Lee AC, Woo MY. National survey of Canadian general surgery program directors regarding focused assessment with sonography for trauma. J Surg Educ. 2009;66(4):193-5. https://doi.org/10.1016/j.jsurg.2009.04.004

19. Wisniewski J, Garnier H. Lifesaving sonography protocols: a pilot course involving undergraduate medical students. Int J Med Stud. 2015;3(1):15-8. https://doi.org/10.5195/ ijms.2015.263

20. Gogalniceanu P, Sheena $Y$, Kashef E, Purkayastha S, Darzi A, Paraskeva P. Is basic emergency ultrasound training feasible as part of standard undergraduate medical education? J Surg Educ. 2010;67(3):152-6. https://doi.org/10.1016/j. jsurg.2010.02.008

21. Krause C, Krause R, Krause R, Gomez N, Jafry Z, Dinh VA. Effectiveness of a 1-hour extended focused assessment with sonography in trauma session in the medical student surgery clerkship. J Surg Educ. 2017;74(6):968-74. https:// doi.org/10.1016/j.jsurg.2017.03.007

22. Deaux K, Emswiller T. Explanations of successful performance on sex-linked tasks: what is skill for the male is luck for the female. J Pers Soc Psychol. 1974;29(1):80-5. https://doi. org/10.1037/h0035733

23. Arora S, Cheung AC, Tarique U, Agarwal A, Firdouse $M$, Ailon J. First-year medical students use of ultrasound or physical examination to diagnose hepatomegaly and ascites: a randomized controlled trial. J Ultrasound. 2017;20(3):199204. https://doi.org/10.1007/s40477-017-0261-6

24. Bahner DP, Goldman E, Way D, Royall NA, Liu YT. The state of ultrasound education in U.S. medical schools: results of a national survey. Acad Med. 2014;89(12):1681-6. https://doi. org/10.1097/ACM.0000000000000414

25. Camilo GB, Toledo GC, Olímpio Júnior H, Dias EN, Oliveira $\mathrm{BL}$, Ferreira JP, et al. Teaching point-of-care transfontanellar ultrasound for pediatricians and medical students. J Pediatr. 2021;97(2):1-7. https://doi.org/10.1016/j.jped.2021.01.006 